\title{
Nitrogen Surface Enrichment of Austenitic Stainless Steel ISO 5832-1: SHTPN vs Low-temperature Plasma Nitriding
}

\author{
Ricardo Fernando dos Reis ${ }^{a *}$, Rodrigo Lupinacci Villanova ${ }^{a}$, \\ Kaiuã Dubyna Costa ${ }^{a}$ Gabriela Costa Durante ${ }^{a}$ \\ ${ }^{a}$ Laboratório de Materiais, Departamento Acadêmico de Mecânica - DAMEC, \\ Universidade Tecnológica Federal do Paraná-UTFPR, Av. Sete de Setembro, 3165, \\ Rebouças, CEP 80230-901, Curitiba, PR, Brazil
}

Received: November 12, 2014; Revised: April 24, 2015

\begin{abstract}
Specimens of ISO 5832-1stainless steel were submitted to low temperature plasma nitriding treatment and Solution Heat Treatment after Plasma Nitriding (SHTPN) process aiming to obtain a S-phase, chromium precipitates-free, surface layer. The following techniques were used for analysis: scanning electron microscopy (SEM), optical microscopy (OM), microhardness, X-ray diffraction (XRD) and wavelength dispersive spectroscopy (WDS) microanalysis. Corrosion resistance was evaluated by means of potentiodynamic anodic polarization and open-circuit measurements of corrosion potential. Results indicated that the S-phase layer with $\mathrm{N}$ concentrations of about $0.9 \mathrm{wt} \%$ and $2 \mu \mathrm{m}$ thick was formed during low temperature plasma nitriding, while layers with concentratios of about $0.45 \mathrm{wt} \%$ of $\mathrm{N}$ and up to $200 \mu \mathrm{m}$ thick resulted from the SHTPN process. Results proved the increase in localized corrosion resistance caused by nitrogen in solid solution for both processes, as well as the deleterious effect caused by the precipitation of chromium nitride.
\end{abstract}

Keywords: SHTPN, plasma nitriding, ISO 5832-1, corrosion behaviour

\section{Introduction}

Austenitic stainless steels have a wide variety of applications because of their excellent corrosion resistance; however, depending on the medium they are exposed to, they are susceptible to crevice and/or localized corrosion. This fact, allied to low hardness and tribological properties, limits their applicability. Several techniques are being used to improve the surface characteristics of these steels, like plasma nitriding at low temperatures ${ }^{1-4}$, ion implantation ${ }^{5}$, and high temperature gas nitriding $(\mathrm{HTGN})^{6}$. More recently, the so-called "Solution Heat Treatment after Plasma Nitriding" (SHTPN) process was proposed as a new method for surface enrichment of nitrogen in solid solution, with good results regarding improvement of corrosion resistance of stainless steels ${ }^{7,8}$.

Plasma nitriding at relatively high temperatures $(723 \mathrm{~K}$ or more) increases the surface hardness with consequent higher wear resistance of these steels; however, it can lead to the formation of $\mathrm{CrN}$ phases. Such precipitation reduces the dissolved chromium content of the metal matrix, impairing the formation of the passive layer characteristic of stainless steels, leading to the decrease in corrosion resistance ${ }^{9,10}$. Most of the beneficial effects of nitrogen in stainless steels are associated to its presence in solid solution (SS $)^{11}$. Hence, the use of plasma nitriding is limited to the low temperature range, where only the formation of the S-phase (also called expanded austenite $-\gamma_{\mathrm{N}}$ ) occurs ${ }^{1,12,13}$.

*e-mail: ricardo@utfpr.edu.br
The S-phase formation on austenitic stainless steels by advanced nitriding treatments has been the subject of several studies $^{1-13}$. Theo focus of this work is not the study of the S-phase itself, rather the SHTPN process as an alternative to low temperature plasma nitriding.

The SHTPN method takes place in two steps: first, plasma nitriding at high temperature (PN) (above $873 \mathrm{~K}$ ) is carried out, in order to produce a thick nitrided layer (regardless the formation of nitrides), followed by the second step, where the material undergoes a solution heat treatment (SHT). This second step causes the diffusion of nitrogen and the consequent formation of a nitrogen-rich, precipitate-free, thick nitrided layer.

A linear correlation between the S-phase microhardness and the nitrogen concentration in solid solution was determined in a previous work ${ }^{7}$. Such correlation can be described by Equation 1, which allows estimating the nitrogen content in solid solution from microhardness measurements.

$\% \boldsymbol{N}=0,0105 \boldsymbol{H} \boldsymbol{V}-2,4116$

The corrosion resistance can be maintained or even increased by treatments that raise the surface nitrogen content in solid solution, as can be depicted from the PREN (Pitting Resistance Equivalent Number). This parameter is relative to the pitting corrosion in media containing chlorides and can be calculated from Equation 2:

PREN $=\% \mathrm{Cr}+3,3(\% \mathrm{Mo})+16(\% \mathrm{~N})$ 
The aim of this work it to compare results obtained by low temperature plasma nitriding and SHTPN, regarding the formation of S-phase and corrosion resistance of ISO 5832-1 ${ }^{14}$ austenitic stainless steel.

\section{Experimental Procedures}

ISO 5832- $1^{14}$ stainless steel cylindrical specimens of $15.0 \mathrm{~mm}$ height and $15.8 \mathrm{~mm}$ diameter were cut from a bar. After cutting, the samples were ground with emery papers and polished with $1 \mu \mathrm{m}$ alumina suspension. Its chemical composition is shown in Table 1. The starting microstructure was fully austenitic, with $210 \mathrm{HV}$ hardness. Initial PREN value, according to the Equation 2, was 28.14.

Before the beginning of the process, the samples were submitted to ultrasound cleaning in ethanol during one hour, in order to eliminate contaminants from the preparation step.

The samples were plasma nitride in a pulsed DC glow discharge. Nitriding parameters for both low temperature and SHTPN processes are summarized in Table 2.

For the low temperature plasma nitriding process, three temperatures were chosen, aiming to obtain a chromium precipitate-free, S-phase layer as thick as possible. The nitriding time was the same used for the SHTPN process ${ }^{7}$. Six samples for each process were produced.

The SHTPN process was carried out as described elsewhere ${ }^{7}$.

After nitriding, samples were cooled down to $573 \mathrm{~K}$ by forced convection in the same gas mixture, and then cooled to room temperature under vaccum.

Samples treated by both processes were longitudinally cut and mounted in resin. They were then prepared using the adequate metallographic process, and the morphology, thickness, and microhardness profiles of the resulting layers were evaluated. The morphology evaluation of the nitrided layer was carried out by means of optical microscopy (OM) and scanning electron microscopy (SEM). Prior to microscopic observation, all samples were electrolytically etched in aqueous solution of oxalic acid (10\%). The thickness of nitrided layers was measured with the aid of an image analyzer software (ImagePro-Plus ${ }^{\circledR}$ ) coupled to the optical microscope. Microhardness measurements (Vickers indenter) were obtained with the use of a microhardness tester Schimadzu model HMV 2. X-ray diffraction was used to identify the phases present after treatments, and a Philips diffractometer was used to obtain the diffractograms with the following parameters: $\mathrm{Cu} \mathrm{k} \alpha$ radiation $(\lambda=1.54060)$, current of $30 \mathrm{~mA}$, voltage of $40 \mathrm{kV}, 2 \theta$-scan step of $0.05^{\circ}$, and scanning angle range of 20 to $120^{\circ}$.

Quantitative measurements of the nitrogen concentrations were conducted for the solubilized samples (SHTPN) by means of wavelength dispersive spectrometry (WDS) microanalysis. Such measurements were made in cross-sections of the samples, from the surface to the core. Further details are described elsewhere ${ }^{7}$. Ferrite content was also measured with the aid of a ferrite content measurement instrument (Feritscope ${ }^{\circledR}$ ), with a detection limit of $0.1 \%$.

The corrosion behavior and the effect of nitrogen in solid solution of treated samples were evaluated by electrochemical tests (potentiodynamic anodic polarization test and open circuit corrosion potential - Ecorr vs time). Prior to electrochemical testing and after nitriding treatments, the samples were ultrasound cleaned in ethanol during one hour in order to eliminate any contaminant from handling, and then cleaned again with acetone. Just before setting the corrosion test cell, samples were smoothly ground with 1200 mesh emery paper in order to standardize the initial passivation condition of the tested surfaces. For the electrochemical tests, a potentiostat-galvanostat IviumStat (Ivium Technologies) connected to a microcomputer was used. The electrolyte was a $0.5 \mathrm{M} \mathrm{NaCl}$ aqueous solution at room temperature, the reference electrode was a $\mathrm{Ag} / \mathrm{AgCl}$ type, and the counter electrode was made of graphite. Before the start of potentiodynamic tests, samples remained immersed in the electrolyte during one hour, until the corrosion potential was reached (Ecorr vs time). The potential scan rate used for the potentiodynamic anodic polarization tests was $0.167 \mathrm{mV} / \mathrm{h}$ $(0.6 \mathrm{~V} / \mathrm{h})$, in accordance to the ASTM G61-86 ${ }^{15}$ Standard. The tests ended when the anodic corrosion current density reached the pre-established value of $100 \mu \mathrm{A} / \mathrm{cm}^{2}$. Three samples of each condition (SHTPN and PN 673) were tested. In order to check the effect the high temperature plasma nitriding process over localized corrosion resistance, a potentiodynamic anodic polarization test was conducted on a PN 1,023 sample, which is characterized by the presence of chromium-nitride precipitates (see Reis, et al. ${ }^{7}$ ).

Table 1. ISO 5832-1 (SC) austenitic stainless steel chemical composition (wt \%).

\begin{tabular}{cccccccc}
\hline $\mathbf{C}$ & $\mathbf{M n}$ & $\mathbf{S i}$ & $\mathbf{C r}$ & $\mathbf{N i}$ & $\mathbf{M o}$ & $\mathbf{N}$ & $\mathbf{F e}$ \\
\hline 0.017 & 1.750 & 0.350 & 17.800 & 14.300 & 2.760 & 0.077 & Balance \\
\hline SC & Starting & & & & &
\end{tabular}

SC - Starting condition

Table 2. Summary of the processes parameters.

\begin{tabular}{|c|c|c|c|c|c|c|}
\hline \multicolumn{4}{|c|}{ Plasma nitriding (PN) } & \multicolumn{3}{|c|}{ Solution heat treatment (SHT) } \\
\hline $\begin{array}{c}\text { Temperature } \\
T(\mathbf{K})\end{array}$ & $\begin{array}{l}\text { Time } \\
t(h)\end{array}$ & $\begin{array}{c}\text { Pressure } \\
P(\mathrm{~Pa})\end{array}$ & Gas mixture & $\begin{array}{c}\text { Temperature } \\
T(\mathbf{K})\end{array}$ & $\begin{array}{c}\text { Time } \\
t(\min )\end{array}$ & $\begin{array}{l}\text { Treatment } \\
\text { media }\end{array}$ \\
\hline 623 & 3 & 533 (4 Torr) & $20 \% \mathrm{~N}_{2} 80 \% \mathrm{H}_{2}$ & -- & -- & -- \\
\hline 673 & 3 & 533 (4 Torr) & $20 \% \mathrm{~N}_{2} 80 \% \mathrm{H}_{2}$ & -- & -- & -- \\
\hline 723 & 3 & 533 (4 Tor) & $20 \% \mathrm{~N}_{2} 80 \% \mathrm{H}_{2}$ & -- & -- & -- \\
\hline 1,023 & 3 & 1,333 (10 Torr) & $90 \% \mathrm{~N}_{2} 10 \% \mathrm{H}_{2}$ & 1,473 & 45 & $\begin{array}{c}\text { Commercial salt } \\
\text { baths }\end{array}$ \\
\hline
\end{tabular}




\section{Results and Discussion}

\subsection{SHTPN}

The results obtained via the SHTPN process are summarized in Table 3. These results are similar to those presented and discussed in a previous work "Nitrogen Surface Enrichment of Austenitic Stainless Steel ISO 5832-1"7. Thus, they won't be discussed in this work.

Figure 1 shows the microstructure of a specimen solubilized after nitriding at $1,023 \mathrm{~K}$. It can be seen from the picture that it's a precipitates-free structure. In order to verify the possible existence of chromium-based precipitates, a long lasting electrolytic etching was made onto the surface. As can be observed from Figure 1, there are no signs of attack in the grain boundary regions. XRD analyses indicate that the microstructure is $100 \%$ austenitic, and ferrite was not detected by means of ferrite content analysis ${ }^{7}$.

According to the values of the Tables 1 and 3, considering the Equation 2, it appears that the PREN value was raised from 28.14 (SC) to 34.11 (SHTPN), indicating improvement in the pitting corrosion resistance.

\subsection{Low-temperature plasma nitriding}

Figure 2 shows micrographs of samples nitrided at 623, 673 and $723 \mathrm{~K}$.

A thin layer on the surface was formed on the surface of samples for all processing temperatures. From XRD analyses, no formation of compound layer was observed, and the diffraction patterns show that there is a relative increase in the amount of S-phase $\left(\gamma_{N}\right)$ with increasing treatment temperatures. The obtained diffractograms are show in Figure 3.

$\mathrm{XRD}$ indicates the formation of a monophasic S-phase layer for the sample nitrided at $723 \mathrm{~K}$ (PN 723). However, the observation of the sample micrograph (Figure 2c), reveals that the area around grain boundaries at the surface layer region was attacked (dark aspect). Even though no chromium compounds were identified by XRD, such attack at grain boundaries is consistent with the presence of chromium precipitates $\left(\mathrm{Cr}_{\mathrm{x}} \mathrm{N}_{\mathrm{y}}\right.$ or $\left.\mathrm{Cr}_{\mathrm{w}} \mathrm{C}_{\mathrm{z}}\right)$ in those areas. It is believed that the amount and/or size of such precipitates are below the detection limits of the XRD apparatus.
Table 4 shows the thickness of the nitrided cases, measured in cross-sections of the samples. The case thickness increased with process temperature, with lower values than those reported by Gontijo et. al. ${ }^{16}$ for AISI 304L and AISI 316L steels at the same treatment conditions. These differences can be explained due to the lower diffusion coefficient and greater solubility of nitrogen (because of the bigger molybdenum content) in the ISO 5832-1 $1^{14}$ steel.

Due to the small thickness of the formed layers, it wasn't possible to obtain the microhardness profile. So, the surface microhardness was measured (see Table 4), even though the layer thickness wouldn't be enough to meet the requirements of the ASTM standard ${ }^{17}$. Since the layer thickness affects the hardness and the measured values on the treated samples reflects the interaction between the layer hardness and part of the substrate, higher hardness values are obtained when the portion of the substrate, which contributes to the measurement, decreases with increasing thickness of the modified layer.

However, for the present work, it is considered that the portion contributing to this effect is smaller when the increased hardness of the material is taken into account. This hardness increase is caused by the solubilization of nitrogen in the S-phase and, for samples nitrided at $723 \mathrm{~K}$, by the presence of chromium compounds.

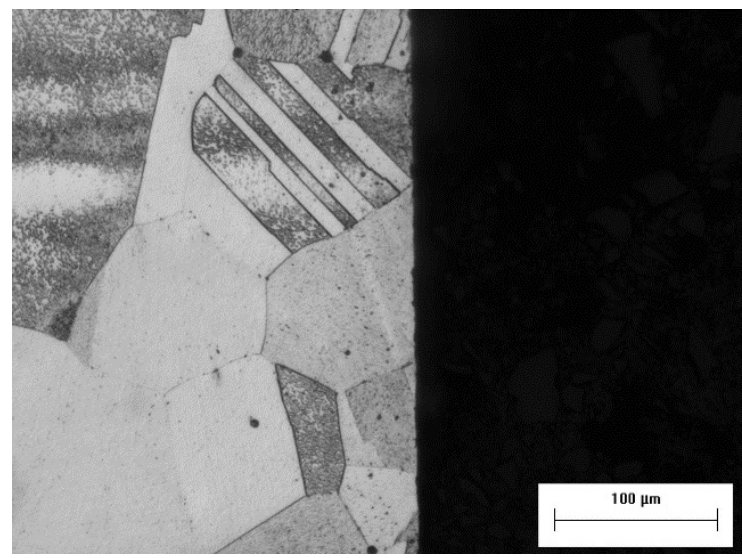

Figure 1. Microstructure of sample SHTPN. Long time electrolytic etching: oxalic acid $10 \%$.

Table 3. Summary of results obtained for the SHTPN process?

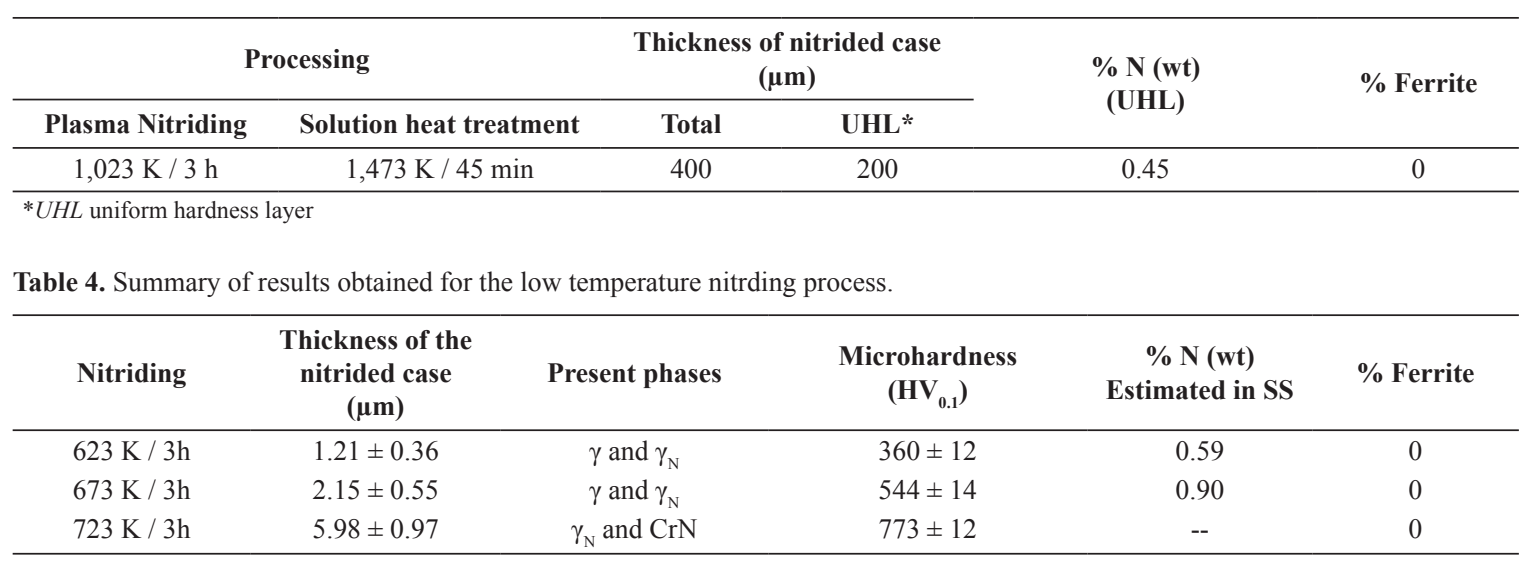




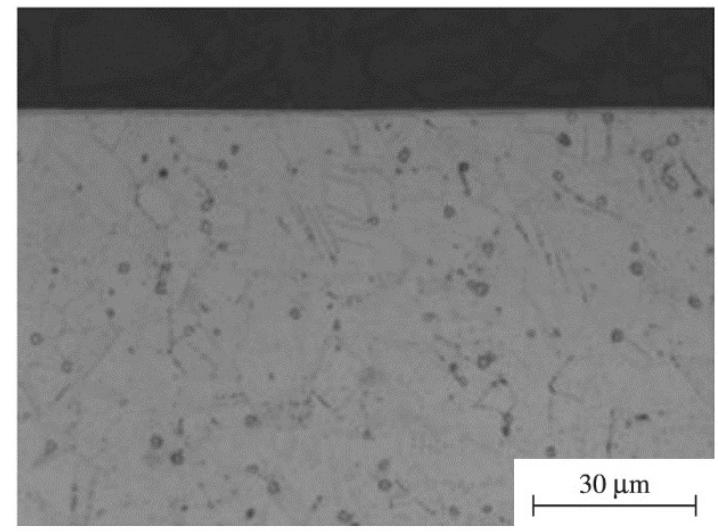

(a) $d$

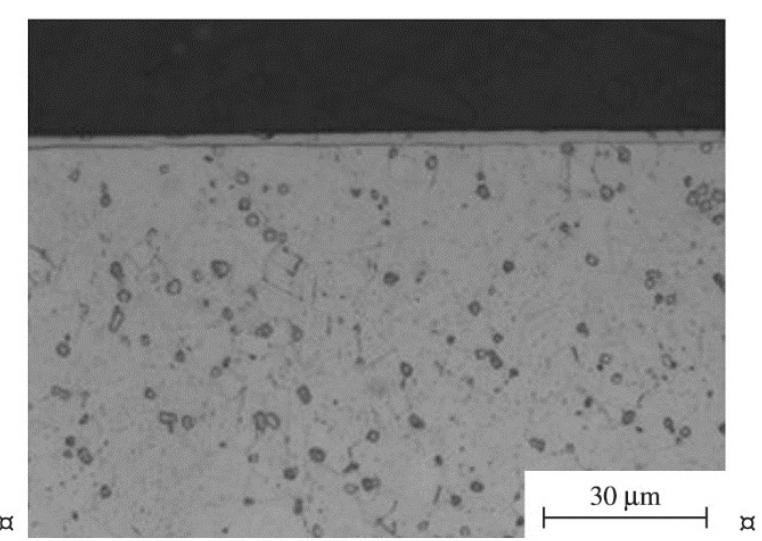

(b) $\mathrm{a}$

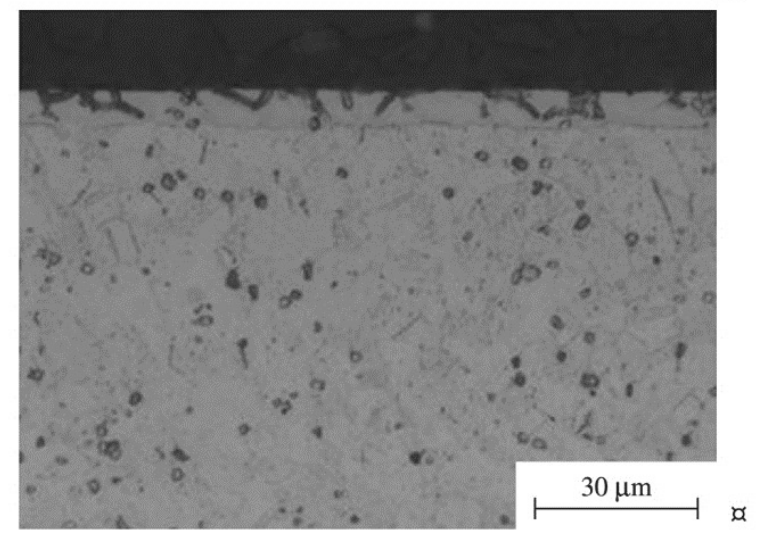

(c) $x$

Figure 2. Micrograph of ISO 5832-1 steel nitrided during 3 hours at: (a) $623 \mathrm{~K}$ (PN 623), (b) $673 \mathrm{~K}$ (PN 673), (c) $723 \mathrm{~K}$ (PN 723 ). Electrolytic etching: oxalic acid $10 \%$.

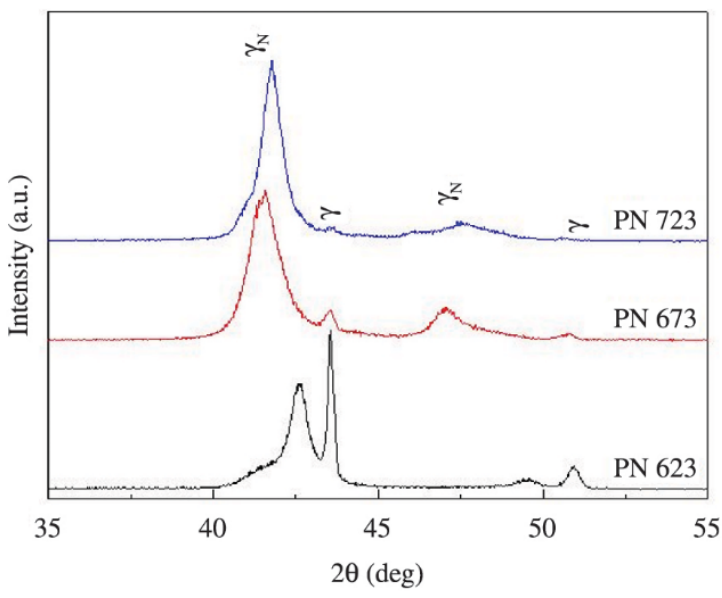

Figure 3. Diffractogram of the ISO 5832-1 steel nitrided during 3 hours at: 623 (PN 623), 673 (PN 673) and $723 \mathrm{~K}$ (PN 723).

For samples nitrided at 423 and $573 \mathrm{~K}$, the nitrogen concentration in the hardened layer can be estimated form Equation 1, provided that the hardness increase is caused by nitrogen in solid solution (SS). These values, as well as the main results obtained from low temperature nitriding regarding the production of the S-phase layer area shown in Table 4.
From the results obtained for the low temperature nitriding process, the condition that led to the formation of a thick, chromium precipitate-free S-phase layer was PN 673 (nitrided at $673 \mathrm{~K}$ ). So, this sample was chosen for the corrosion tests.

Based on the steel chemical composition (Table 1), the measured nitrogen content (Table 4), and Equation 2, it can be stated that the low temperature plasma nitriding led to an increase in PREN, as well as the SHTPN process. PREN changed from 28.14 to 36.53 for samples nitrided at $623 \mathrm{~K}$ (PN 623), and from 28.14 to 41.31 for samples nitrided at $673 \mathrm{~K}$ (PN 673). Again, there is in an indicator of the corrosion resistance improvement for this sample.

\subsection{Electrochemical tests}

\subsubsection{Open circuit corrosion potential (Ecorr vs Time)}

The open circuit corrosion potential (Ecorr $v s$ time) was measured for the following test conditions: starting condition (SC), SHTPN, PN 673, PN 1,023. Obtained results are shown in Figure 4.

Except for the sample PN 1,023, the results indicate that the open circuit potential is less noble at the beginning of the test, and increases with time, stabilizing in a more noble potential. This shows that the material is passivating in this medium, i.e., a passive layer is being formed on the surface of the material during the test. 
Measured open circuit potentials show that there is a little variation among tested conditions - starting condition, low temperature nitriding, and SHTPN. The greatest potential was measured for the sample PN 673, which is consistent with the grater surface nitrogen concentration in solid solution for this condition. The SHTPN process didn't caused major changes in the open circuit potential when compared to the starting condition (SC).

A major discrepancy on the results was verified for the sample nitrided at $1,023 \mathrm{~K}(\mathrm{PN} 1,023)$, where the open circuit potential decreases to values far below the others. This decrease in the potential can be explained by the formation of chromium-nitrides precipitates in the compound layer (see Figure 4 of the article Reis et. al. for further details ${ }^{7}$ ), thus reducing the passivation of the material and its resistance to uniform corrosion.

\subsubsection{Potentiodynamic anodic polarization}

The potentiodynamic anodic polarization test allow comparing the susceptibility to localized corrosion as a function of the nitrogen surface enrichment caused by the different treatments that the samples were submitted.

Figure 5 shows the curves obtained in the potentiodynamic polarization tests for the ISO 5832- $1{ }^{14}$ steel in the following conditions: SC, SHTPN, low temperature plasma nitriding (PN 673), and high temperature plasma nitriding (PN 1,023).

The electrochemical behavior verified for the starting condition (SC) is consistent with materials that have a defined critical pitting corrosion potential (Ec). This potential corresponds to the value where the breakdown of the passive layer occurs, and localized corrosion starts to happen. This potential is characterized by a sharp increase in the corrosion current density.

The critical pitting corrosion potential wasn't reached for conditions PN 673 and SHTPN. The sudden increase in current density observed close to $1,400 \mathrm{mV}(\mathrm{Ag} / \mathrm{AgCl})$ should be associated to the water dissociation, according to the reaction shown in Equation 3. When this reaction occurs at the sample surface, it is impossible to say if the increase in current density is due to passivity breakdown or the reaction itself, which limits the test to potentials of this magnitude. However, it becomes evident that conditions PN 673 and SHTPN have higher pitting corrosion resistance than the starting condition (potentials greater than $1,300 \mathrm{mV}$ $(\mathrm{Ag} / \mathrm{AgCl}))$.

$$
2 \mathrm{H}_{2} \mathrm{O} \rightarrow \boldsymbol{O}_{2}+4 \boldsymbol{H}^{+}+4 \boldsymbol{e}^{-}
$$

Table 5 summarizes the results obtained in the potentiodynamic anodic polarizations tests.

The gain of localized corrosion resistance for the conditions PN 673 and SHTPN can be associated to the presence of nitrogen in solid solution and the increase in PREN, as discussed before.

Differently from what was observed in the previous test (Ecorr vs time), where a better behavior in terms of uniform corrosion was observed for the PN 673 condition, it was impossible to distinguish the behavior in terms of localized corrosion (critical pitting corrosion potential) of the low temperature plasma nitriding (PN 673) and SHTPN conditions. Both treatments resulted in significant improvement

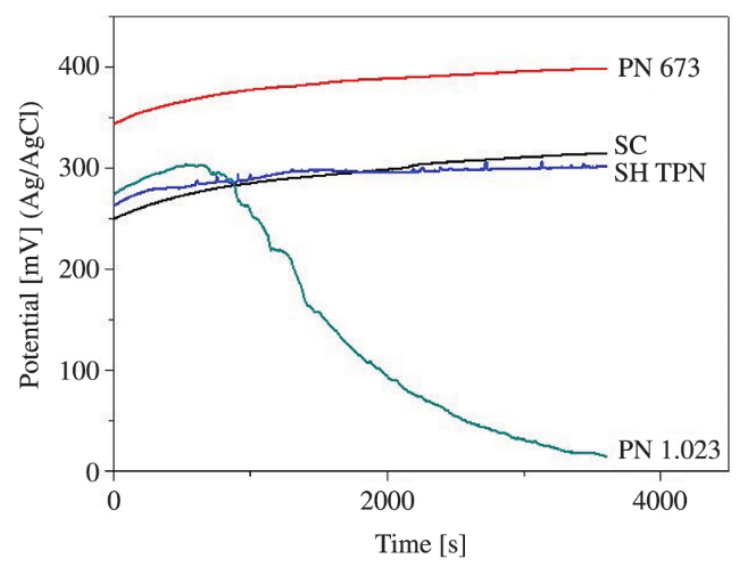

Figure 4. Comparative between the open circuit corrosion potential for the studied conditions.

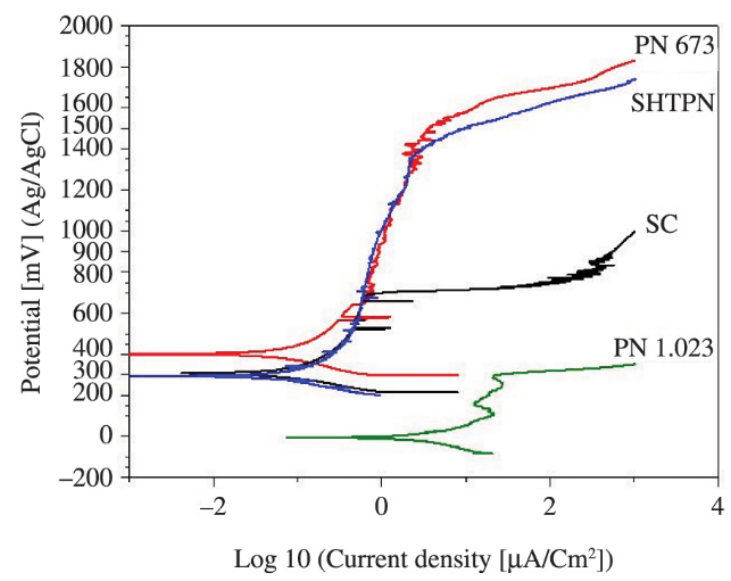

Figure 5. Potentiodynamic anodic polarization curves.

Table 5. Critical pitting corrosion potentials obtained from the potentiodynamic anodic polarization curves.

\begin{tabular}{cc}
\hline Condition & $\boldsymbol{E}_{\boldsymbol{C}}(\mathbf{m V}(\mathbf{A g} / \mathbf{A g C l}))$ \\
\hline SC & $686.8 \pm 0.6$ \\
NP 673 & $>1,300$ \\
SHTPN & $>1,300$ \\
\hline
\end{tabular}

of the localized corrosion resistance, as observed by the increase in the critical pitting corrosion potential. The main difference between studied conditions is the thickness of the nitrogen-rich layer. For the SHTPN condition, this thickness is about 150-250 times greater than those produced by low temperature plasma nitriding (see Tables 3 and 4). Because of this significant difference, an increase in the lifespan of treated components submitted to wear is expected. Further investigations regarding the cavitation erosion resistance of samples treated under the same conditions of this work are being conducted.

As expected, the localized corrosion resistance of the samples nitrided at high temperature (PN 1,023) decreased significantly, since the critical pitting corrosion potential dropped from about $686.8 \mathrm{mV}(\mathrm{Ag} / \mathrm{AgCl}$, starting condition) to 
about $291.2 \mathrm{mV}(\mathrm{Ag} / \mathrm{AgCl})$ for this condition. This reduction is due to the precipitation of chromium-nitride compounds, which reduces the chromium content in solid solution in the steel matrix close to the precipitates, impairing the localized corrosion resistance ${ }^{7}$.

Besides that, an increase in current density was also observed for this condition, confirming the low corrosion resistance of high temperature nitrided samples.

\section{Conclusions}

- The surface S-phase $\left(\gamma_{\mathrm{N}}\right)$ layer was formed for both SHTPN and low temperature plasma nitriding processes, but with significant differences between them, especially regarding their thicknesses. For the SHTPN process, thicknesses of up to $200 \mu \mathrm{m}$ were obtained, while for low temperature nitriding an estimated thickness of about $2 \mu \mathrm{m}$ was produced for the PN 673 condition.

- The nitrogen concentration in the modified layer was also different for different processes. A concentration of $0.4 \mathrm{wt} \%$ of nitrogen was measured for the SHTPN process, while the estimated value for low temperature nitriding it was $0.59 \mathrm{wt} \%$ (PN 673 condition).

\section{References}

1. Larisch B, Brusky U and Spies HJ. Plasma nitriding of stainless steels at low temperatures. Surface and Coatings Technology. 1999; 116-119:205-211. http://dx.doi.org/10.1016/S02578972(99)00084-5.

2. Menthe E, Bulak A, Olfe J, Zimmermann A and Rie KT. Improvement of the mechanical properties of austenitic stainless steel after plasma nitriding. Surface and Coatings Technology. 2000; 133-134:259-263. http://dx.doi.org/10.1016/S02578972(00)00930-0.

3. Olzon-Dionysio M, Campos M, Higa OZ, Cunha TF and Souza SD. Investigating the correlation between some of the properties of plasma nitrided AISI $316 \mathrm{~L}$ stainless steeL. Materials Research. 2013; 16(5):1052-1057. http://dx.doi. org/10.1590/S1516-14392013005000081.

4. Mendes AF, Scheuer CJ, Joanidis IL, Cardoso RP, Mafra M, Klein NA, et al. Low-temperature plasma nitriding of sintered PIM 316L austenitic stainless steel. Materials Research. 2014; 17(Suppl. 1):100-109. http://dx.doi.org/10.1590/S151614392014005000064 .

5. Abreu CM, Cristóbal MJ, Merino P, Nóvoa XR, Pena G and Pérez MC. Electrochemical behaviour of an AISI 304L stainless steel implanted with nitrogen. Electrochimica Acta. 2008; 53(20):60006007. http://dx.doi.org/10.1016/j.electacta.2008.03.064.

6. Garzón CM and Tschiptschin AP. Nitretação em alta temperatura de aços inoxidáveis. Revista Matéria. 2005; 10(4):502-525.

7. Reis RF, Maliska AM and Borges PC. Nitrogen surface enrichment of austenitic stainless steel ISO 5832-1. Journal of Materials Science. 2011; 46(3):846-854. http://dx.doi. org/10.1007/s10853-010-4827-3.

8. Borges PC and Rocha LA. Solution heat treatment of plasma nitrided 15-5PH stainless steel - part I: improvement of the corrosion resistance. Kovové Materiály. 2011; 49:107-117.
- The best uniform corrosion behavior was obtained for the PN 673 condition, which is related to the higher surface concentration of nitrogen in solid solution.

- The localized corrosion resistance, as measured by the critical pitting corrosion potential can be significantly increased by the presence of nitrogen in solid solution, for both SHTPN and low temperature nitriding processes.

- It is believed that the SHTPN process is able to increase the lifespan of components subjected to wear, when compared to low temperature nitriding, because of the much bigger thickness of the transformed layer.

- The precipitation of chromium nitrides in stainless steels reduces both localized (pitting) and uniform corrosion resistance of the material.

\section{Acknowledgements}

The authors wish to thank Villares Metals for the donation of the material employed in the research and SOCIESC - SC for the use of the salt baths for the solution heat treatment.

9. Liang W, Juncai S and Xiaolei X. Low pressure plasma arc source ion nitriding compared with glow-discharge plasma nitriding of stainless steel. Surface and Coatings Technology. 2001; 145(13):31-37. http://dx.doi.org/10.1016/S0257-8972(01)01283-X.

10. Liang W. Surface modification of AISI 304 austenitic stainless steel by plasma nitriding. Applied Surface Science. 2003; 211(14):308-314. http://dx.doi.org/10.1016/S0169-4332(03)00260-5.

11. Gavriljuk VG and Berns H. High nitrogen steels: structure, properties, manufacture, applications. Berlin: Springer-Verlag Berlin Heildelberg; 1999.

12. Xi YT, Liu DX and Han D. Improvement of mechanical properties of martensitic stainless steel by plasma nitriding at low temperature. Acta Metallurgica Sinica. 2008; 21(1):21-29. http://dx.doi.org/10.1016/S1006-7191(08)60015-0.

13. Bernardelli EA, Borges PC, Fontana LC and Floriano JB. Role of plasma nitriding temperature and time in the corrosion behaviour and microstructure evolution of 15-5 PH stainless steel. Kovové Materiály. 2010; 48(2):105-116.

14. International Organization for Standardization. Implants for sugery-metallic materials - part 1: wrought stainless steel. Switzerland; 1997.

15. American Society for Testing and Materials. Standard test method for conducting cyclic potentiodynamic polarization measurements for localized corrosion susceptibility of Iron-, Nickel-, or Cobalt-Based alloys. West Conshohocken; 1986.

16. Gontijo LC, Machado R, Casteletti LC, Kuri SE and Nascente PAP. Comparação entre os comportamentos dos aços inoxidáveis AISI 304L e AISI 316L nitretados a plasma. Revista Brasileira de Aplicações de Vácuo. 2007; 26(3):145-150.

17. American Society for Testing and Materials. Standard test method for knoop and vickers hardness of materials. West Conshohocken; 2011. 